\title{
Corrigendum: The Structure of Online Information Behind Social Crises
}

\author{
Juan Pablo Cárdenas ${ }^{1,2}$, Gastón Olivares ${ }^{1,2,3}$, Gerardo Vidal ${ }^{2,4}$, Carolina Urbina ${ }^{5}$ and \\ Miguel Fuentes ${ }^{2,6,7,8 *}$
}

${ }^{1}$ Net-Works, Viña del Mar, Chile, ${ }^{2}$ Complex Society Lab, Viña del Mar, Chile, ${ }^{3}$ Grupo de Sistemas Complejos, Escuela Técnica Superior de Ingeniería Agronómica, Alimentaria y de Biosistemas, Universidad Politécnica de Madrid, Madrid, Spain, ${ }^{4}$ Pontificia Universidad Católica de Valparaíso, Valparaíso, Chile, ${ }^{5}$ Psicología, Facultad de Educación y Ciencias Sociales, Universidad Andrés Bello, Viña del Mar, Chile, ${ }^{6}$ Instituto de Investigaciones Filosóficas, Buenos Aires, Argentina, ${ }^{7}$ Santa Fe Institute, Santa Fe, NM, United States, ${ }^{8}$ Instituto de Sistemas Complejos de Valparaíso, Valparaíso, Chile

Keywords: social crises, complexity, social networks, polarization, thematic networks, early-warning

A corrigendum on

The Structure of Online Information Behind Social Crises

by Cárdenas J. P., Olivares G., Vidal G., Urbina C., and Fuentes M. (2021). Front. Phys. 9:650648. doi: $10.3389 /$ fphy.2021.650648

In the published article, there was an error regarding the affiliations for Miguel Fuentes. As well as having affiliations 2, 6 and 7, they should also have affiliation 8, 'Instituto de Sistemas Complejos de Valparaíso, Valparaíso, Chile'.

In addition, there were errors in some of the references. Reference 23 "Lagroye J. La Legimitation.

Edited and reviewed by: Haroldo V. Ribeiro, State University of Maringá, Brazil

*Correspondence: Miguel Fuentes fuentesm@santafe.edu

Specialty section:

This article was submitted to Social Physics,

a section of the journal

Frontiers in Physics

Received: 09 October 2021 Accepted: 02 November 2021 Published: 17 December 2021

Citation:

Cárdenas JP, Olivares G, Vidal G, Urbina $C$ and Fuentes M (2021) Corrigendum: The Structure of Online Information Behind Social Crises.

Front. Phys. 9:792200

doi: 10.3389/fphy.2021.792200
In: M. Grawitz, and J. Leca, editors. Traité de science politique. Paris, France: PUF (1985) Vol. 1. p. 395-467" should have been removed from the reference list.

A correction has been made to Section 2: Social Crises. A Brief View From Social Sciences, paragraphs 2 and 3:

"Furthermore, it seems clear that any of these definitions consider the phenomenon as a "process" which, according to the discussion in [12] for example, occurs in stages: integration, disintegration, rupture and reintegration.

From sociological theory [12-22], social crises have three properties that define them as such: 1) the conjunctural desectorization of the social space, 2) structural uncertainty and, 3) the processes of deobjectivation; all selective, observable and with a given trend."

The authors apologize for these errors and state that they do not change the scientific conclusions of the article in any way. The original article has been updated.

Publisher's Note: All claims expressed in this article are solely those of the authors and do not necessarily represent those of their affiliated organizations, or those of the publisher, the editors and the reviewers. Any product that may be evaluated in this article, or claim that may be made by its manufacturer, is not guaranteed or endorsed by the publisher.

Copyright (C) 2021 Cárdenas, Olivares, Vidal, Urbina and Fuentes. This is an open-access article distributed under the terms of the Creative Commons Attribution License (CC BY). The use, distribution or reproduction in other forums is permitted, provided the original author(s) and the copyright owner(s) are credited and that the original publication in this journal is cited, in accordance with accepted academic practice. No use, distribution or reproduction is permitted which does not comply with these terms. 